\title{
Trends in the prevalence of obesity among Belgian men at work, 1977-1992
}

\author{
MC Stam-Moraga ${ }^{1}$, J Kolanowski ${ }^{3}$, M Dramaix ${ }^{2}$, S De Henauw ${ }^{4}$, D De Bacquer ${ }^{4}$, G De Backer ${ }^{4}$ and MD Kornitzer $^{4}$ \\ Laboratories of ${ }^{1}$ Epidemiology and Social Medicine and ${ }^{2}$ Medical Statistics, School of Public Health, Université Libre de Bruxelles; \\ ${ }^{3}$ School of Medicine, Université Catholique de Louvain, Brussels; and ${ }^{4}$ Department of Public Health, University of Gent, Belgium
}

\begin{abstract}
OBJECTIVE: To assess trends in average body mass index (BMI) and the prevalence of obesity between 1977 and 1992, in middle-aged Belgian men at work.

SUBJECTS: A subsample of men at work, aged 40-54 y extracted from the base-line data from four independent prospective studies, each representing a period (Physical Fitness Study (1977-1978), Belgian Interuniversity Research on Nutrition and Health (BIRNH) (1979-1984), Multinational Monitoring of Trends and Determinants in Cardiovascular Diseases (MONICA) (1986-1991) and ORCA (1992-1993)).

DESIGN: Linear regression of the average body mass index $\left(\mathrm{kg} / \mathrm{m}^{2}\right)$ and logistic regression of the prevalence of obesity $\left(B M I \geq 30 \mathrm{~kg} / \mathrm{m}^{2}\right)$. Independent variables taken into account in multivariate analysis were: age, educational level, marital status and region.

RESULTS: In this subsample of Belgian men at work, aged 40-54 y, prevalence of obesity increased from $9.2 \%$ in 1977-1978 to $14.5 \%$ in 1992-1993. This rise was present in each five-year age group, in both regions and in all educational groups, but strongest in the lowest educated. After adjustment for sociodemographic covariables, it was estimated that with regard to $1977-1978$, the proportion of men with a $B M I \geq 30 \mathrm{~kg} / \mathrm{m}^{2}$ doubled over the $15-y e a r$ period (odds ratio OR (95\% confidence intervals, $95 \% \mathrm{CI})$ ): $1.98(1.40 ; 2.80)$.

CONCLUSION: Keeping in mind that the trends have been calculated from data from four different studies, presenting some shortcomings, prevalence of obesity has increased between 1977-1992 in men aged 40-54 y at work. This rise is particularly pronounced in the lower educated groups.
\end{abstract}

Keywords: trends; obesity; body mass index

\section{Introduction}

Data from a recent World Health Organisation (WHO) report ${ }^{1}$ estimated that the prevalence of obesity in Europe has reached $15-20 \%$ of the middle-aged population. Moreover, available trend data from European countries (UK, ${ }^{2}$ The Netherlands, ${ }^{3,4}$ Finland, ${ }^{5}$ Sweden, ${ }^{6}$ Germany, ${ }^{7}$ Spain $^{8}$ ) as well as from affluent countries outside Europe (US, ${ }^{9,10}$ Canada, ${ }^{11}$ Australia $^{12}$ ) consistently suggest an increase in the prevalence of obesity.

In Belgium, information on these trends is lacking. In order to confirm the trends described in most industrialized countries, baseline data from four prospective cohort studies (the Physical Fitness study, 1977-1978 (PFS), the Belgian Interuniversity Research on Nutrition and Health, 1979-1984 (BIRNH), the Multinational Monitoring of Trends and Determinants in Cardiovascular Diseases, 19861991 (MONICA) and the ORCA study, 1992-1993) were used to investigate trends in body mass index

Correspondence: Margaretha C Stam-Moraga, 18 Quai du Cheval-Blanc, CH-1227 Carouge/GE, Switzerland. Received 20 January 1998; revised 29 April 1998; accepted 22 May 1998
(BMI, $\mathrm{kg} / \mathrm{m}^{2}$ ) and in the prevalence of obesity between 1977-1992 among middle-aged Belgian working men.

\section{Subjects and methods}

The time trends were derived from four independent studies, carried out during successive periods by two collaborating universities. Characteristics of the studies are summarized in Table 1.

In brief, the PFS (1977-1978) was conducted in several factories (including electrical plants, chemical industries and insurance companies) situated throughout Belgium. In total 3179 men aged 40$55 \mathrm{y}$, regularly employed by factories, were invited to participate and $74.3 \%$ attended the screening examination. ${ }^{13}$ The BIRNH study (1979-1984) was performed in a $10 \mathrm{y} /$ gender stratified sample of the general Belgian population aged $25-74 \mathrm{y} .{ }^{14}$ Participation rate was $36.5 \%$. The three surveys of the MONICA project (1986-1991) were carried out in three independent general population studies aged 25-64 y of two towns in Belgium (Gent and Charleroi). ${ }^{15}$ Average response rate was $41.2 \%$. For the present analysis, data from the three MONICA 
Table 1 Characteristics of the studies

\begin{tabular}{lclclc}
\hline Study & Period & Study population & Age range (y) & Region & N subsample \\
\hline Physical Fitness & $1977-1978$ & Industry, men & $40-55$ & All through Belgium \\
BIRNH & $1979-1984$ & General population & $25-74$ & Whole Belgium & 2224 \\
MONICA & $1986-1991$ & General population & $25-64$ & Two towns (Charleroi + Gent) \\
ORCA & $1992-1993$ & Industry, men & $35-59$ & North Belgium & 648 \\
\end{tabular}

$\mathrm{BIRNH}=$ Belgian Interuniversity Research on Nutrition and Health; MONICA = Multinational Monitoring of Trends and Determinants in Cardiovascular Diseases.

surveys were pooled. The ORCA study (1992-1993) concerns 768 men aged 35-59y (participation rate $83 \%$ ), regularly employed in four companies (two stations of a train repair and maintenance service company, a privately owned chemical company and a metal plating factory) situated in the North of Belgium. $^{16}$

To reach a maximum of comparability between studies, we extracted from the general population studies all men aged $40-54 \mathrm{y}$, employed or freelance (1659 men in BIRNH and 648 from the MONICA surveys). In the industrial population all men aged 40-54y were selected (2224 men in PFS and 406 from ORCA).

In all studies, height and weight of subjects without shoes and in underwear or light indoor clothing were measured by trained paramedics. Obesity was defined as a $B M I \geq 30 \mathrm{~kg} / \mathrm{m}^{2}$. Level of education and marital status were collected in each study using the same standardized questionnaire. Categorical covariables were classified as follows: age $(40-44 \mathrm{y}, 45-49 \mathrm{y}$, $50-54 \mathrm{y}$ ), educational level according to the highest grade completed (elementary, secondary, university), region (Dutch speaking, French speaking) and marital status (single, married, divorced or separated, widowed). Details on the studies design and sampling have been published elsewhere. ${ }^{13-16}$

\section{Statistical analysis}

Univariate analysis of mean BMI by study periods, and stratified analyses by sociodemographic covariables, were performed by analysis of variance. In addition, multiple means comparisons were performed using the Newman-Keuls Student test. ${ }^{17}$ A multiple linear regression model was fitted to evaluate the effect of period on mean BMI, independently from the covariables. Period 1977-1978 was taken as reference and the estimated parameters show the difference with regard to this reference. Regression assumptions were checked through graphical inspection of the Pearson residuals.

For the proportion of obesity, multivariate analysis was performed by estimating the odds ratios (OR) and $95 \%$ confidence intervals $(95 \% \mathrm{CI})$ of the prevalence of a $\mathrm{BMI} \geq 30 \mathrm{~kg} / \mathrm{m}^{2}$ in a multilogistic regression model, adjusted for age, educational level, region and marital status. The first study period was chosen as reference category. All analyses were performed using the SPSS 4.0 software.

\section{Results}

The crude mean BMI increased by $0.94 \mathrm{~kg} / \mathrm{m}^{2}$ over the $15 \mathrm{y}$ period $(P<0.0001)$, from $25.67 \mathrm{~kg} / \mathrm{m}^{2}$ in $1977-1978$ to $26.42 \mathrm{~kg} / \mathrm{m}^{2}, 26.44 \mathrm{~kg} / \mathrm{m}^{2}$ and 26.61 $\mathrm{kg} / \mathrm{m}^{2}$, respectively in 1979-1984, 1986-1991 and 1992-1993. This positive trend in mean BMI, contributed substantially to the rise in the prevalence of obesity (shown in Figure 1).

When analyzing these trends in different sociodemographic subgroups, mean BMI and the proportion of men with BMI $\geq 30 \mathrm{~kg} / \mathrm{m}^{2}$ increased in each five-year age category, in the Dutch speaking, as well as in the French speaking region, especially among single and married men and in every educational level group (Table 2 and Table 3 ).

In multivariate analysis (Table 4), adjusted for age, region, marital status and educational level, the average difference in BMI between the first and the last study period was estimated at $0.99 \mathrm{~kg} / \mathrm{m}^{2}$. This represents a $4 \%$ increase over the $15 \mathrm{y}$ period and corresponds to a $3.2 \mathrm{~kg}$ weight gain for a $1.80 \mathrm{~m}$ man. With regard to 1977-1978, the proportion of obese men almost doubled in 1992-1993 (OR (CI): 1.98 (1.40; 2.80)).

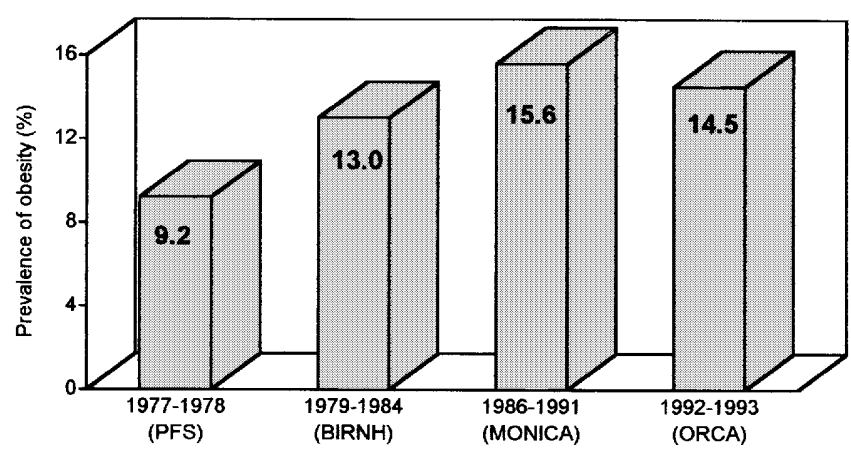

Figure 1 Age-adjusted prevalence of obesity (body mass index, $B M I \geq 30 \mathrm{~kg} / \mathrm{m}^{2}$ ) for the four study periods, 1977-1978, 1979-1984, 1986-1991, 1992-1993. Belgian men at work aged 40-54 y. PFS = Physical Fitness Study; BIRNH = Belgian Interuniversity Research on Nutrition and Health; MONICA = Multinational Monitoring of Trends and Determinants in Cardiovascular Diseases. 
Table 2 Body mass index (BMI) in Belgian men at work by age, region, marital status and educational level for four study periods, 1977-1984, 1979-1984, 1986-1991 and 1992-1993 (mean standard deviation (s.d.))

\begin{tabular}{|c|c|c|c|c|c|c|c|c|c|}
\hline & \multicolumn{2}{|c|}{$\begin{array}{c}P F S \\
1977-1978\end{array}$} & \multicolumn{2}{|c|}{$\begin{array}{c}\text { BIRNH } \\
1979-1984\end{array}$} & \multicolumn{2}{|c|}{$\begin{array}{c}\text { MONICA } \\
1986-1991\end{array}$} & \multicolumn{2}{|c|}{$\begin{array}{c}\text { ORCA } \\
1992-1993\end{array}$} & \multirow[b]{2}{*}{$P^{\mathrm{a}}$} \\
\hline & $n$ & Mean (s.d.) & $n$ & Mean (s.d.) & $n$ & Mean (s.d.) & $n$ & Mean (s.d.) & \\
\hline \multicolumn{10}{|l|}{ Age category (y) } \\
\hline $40-44$ & 799 & $25.49(2.91)$ & 544 & $26.11(3.37)$ & 225 & $26.05(3.92)$ & 212 & $26.35(3.35)$ & $* *, \mathrm{~b}$ \\
\hline $45-49$ & 806 & $25.75(3.03)$ & 595 & $26.75(3.30)$ & 207 & $26.56(3.67)$ & 132 & $26.92(3.11)$ & $* * *, \mathrm{~b}$ \\
\hline $50-54$ & 619 & $25.78(3.24)$ & 520 & $26.35(3.14)$ & 216 & $26.74(3.54)$ & 62 & $26.88(3.18)$ & $* *, \mathrm{c}$ \\
\hline \multicolumn{10}{|l|}{ Region } \\
\hline Dutch speaking & 1579 & $25.77(3.10)$ & 1038 & $26.51(3.24)$ & 406 & $26.30(3.42)$ & 406 & $26.61(3.25)$ & $* * *, \mathrm{~b}$ \\
\hline French speaking & 645 & $25.42(2.91)$ & 621 & $26.27(3.35)$ & 242 & $26.68(4.18)$ & - & - & $* * *, \mathrm{c}$ \\
\hline \multicolumn{10}{|l|}{ Marital status } \\
\hline Single & 82 & $24.88(3.15)$ & 80 & $27.01(3.85)$ & 67 & $26.47(5.04)$ & 30 & $27.81(4.50)$ & $* *, \mathrm{~b}$ \\
\hline Married & 2051 & $25.72(3.02)$ & 1484 & $26.42(3.24)$ & 535 & $26.48(3.55)$ & 359 & $26.52(3.14)$ & $* * *, \mathrm{~b}$ \\
\hline Divorced/separated & 69 & $24.82(3.06)$ & 66 & $25.98(3.17)$ & 41 & $25.57(3.16)$ & 14 & $26.24(2.73)$ & NS \\
\hline Widowed & 21 & $26.82(4.80)$ & 16 & $25.93(3.96)$ & 5 & $29.18(4.76)$ & 2 & $28.97(1.06)$ & NS \\
\hline \multicolumn{10}{|l|}{ Educational level } \\
\hline Elementary & 587 & $25.95(3.23)$ & 984 & $26.69(3.32)$ & 152 & $27.10(4.24)$ & 44 & $26.68(3.81)$ & $* * *, \mathrm{c}$ \\
\hline Secondary & 779 & $25.60(3.02)$ & 391 & $26.00(3.18)$ & 289 & $26.59(3.74)$ & 334 & $26.59(3.17)$ & $* * *, \mathrm{~d}$ \\
\hline University & 826 & $25.51(2.93)$ & 275 & $26.05(3.19)$ & 207 & $25.76(3.16)$ & 28 & $26.75(3.35)$ & $*, \mathrm{e}$ \\
\hline
\end{tabular}

NS: not statistically significant; ${ }^{*} P<0.05 ;{ }^{*} P<0.01 ; * * * P<0.0001$.

aSignificant test means: at least two groups differ significantly.

Multiple means comparisons:

${ }^{\mathrm{b}}$ mean BMI of PFS differs significantly from means of the three other periods;

${ }^{c}$ mean BMI of BIRNH and MONICA differ significantly from mean of PFS:

${ }^{d}$ mean BMI of PFS and BIRNH differ significantly from mean of MONICA and ORCA;

emean BMI of BIRNH differs significantly from mean of PFS.

PFS = Physical Fitness Study; BIRNH= Belgian Interuniversity Research on Nutrition and Health; MONICA = Multinational Monitoring of Trends and Determinants in Cardiovascular Diseases.

Table 3 Prevalence of obesity $\left(\mathrm{BMI} \geq 30 \mathrm{~kg} / \mathrm{m}^{2}\right)$ in Belgian men at work by age, region, marital status and education level for the four study periods, 1977-1984, 1979-1984, 1986-1991 and 1992-1993

\begin{tabular}{|c|c|c|c|c|c|}
\hline & $\begin{array}{c}P F S \\
1977-1978 \\
\text { (\%) }\end{array}$ & $\begin{array}{c}\text { BIRNH } \\
1979-1984 \\
\text { (\%) }\end{array}$ & $\begin{array}{c}\text { MONICA } \\
1986-1991 \\
\text { (\%) }\end{array}$ & $\begin{array}{c}\text { ORCA } \\
1992-1993 \\
\text { (\%) }\end{array}$ & $P$ trends \\
\hline \multicolumn{6}{|l|}{ Age category (y) } \\
\hline $40-44$ & 7.3 & 11.0 & 12.9 & 9.4 & * \\
\hline $45-49$ & 7.9 & 14.5 & 15.5 & 15.9 & $* * *$ \\
\hline $50-54$ & 9.0 & 11.3 & 15.3 & 22.6 & $* *$ \\
\hline \multicolumn{6}{|l|}{ Region } \\
\hline Dutch speaking & 8.7 & 12.9 & 11.8 & 13.5 & $* *$ \\
\hline French speaking & 6.4 & 11.4 & 19.0 & - & $* * *$ \\
\hline \multicolumn{6}{|l|}{ Marital status } \\
\hline Single & 4.9 & 20.0 & 16.4 & 13.3 & * \\
\hline Married & 8.0 & 11.9 & 14.4 & 13.1 & $* * *$ \\
\hline Divorced/separated & 5.8 & 12.1 & 9.8 & 7.1 & NS \\
\hline Widowed & 23.8 & 25.0 & 40.0 & - & NS \\
\hline \multicolumn{6}{|l|}{ Educational level } \\
\hline Elementary & 10.1 & 14.7 & 21.7 & 18.2 & $* *$ \\
\hline Secondary & 7.6 & 8.4 & 13.8 & 13.2 & $* *$ \\
\hline University & 6.8 & 9.5 & 10.1 & 10.7 & NS \\
\hline
\end{tabular}

NS: not statistically significant; ${ }^{*} P<0.05 ;{ }^{* *} P<0.01 ;{ }^{*} *{ }^{*} P<0.0001$

$\mathrm{PFS}=$ Physical Fitness Study; BIRNH=Belgian Interuniversity Research on Nutrition and Health; MONICA $=$ Multinational Monitoring of Trends and Determinants in Cardiovascular Diseases.

\section{Discussion}

Our results have to be considered with caution as methodologically our approach presents some shortcomings. The four samples, each representing a period of years, might not be completely comparable, especially concerning the region represented. Belgium is indeed cut in two by a horizontal language border. The Northern region is Dutch-speaking and the Southern region is French-speaking. Between North and
South, differences in lifestyle factors and biological parameters have been reported ${ }^{18-22}$ (that is, higher butter consumption in the South, higher margarine consumption in the North and higher serum-cholesterol levels in the South); it was therefore important to introduce the variable 'region' as a potential confounder in multivariate analysis. We were however concerned by the question: 'Within the two respective regions, does the BMI of the inhabitants in more specific places (such as the town Charleroi in the South and the Gent in the North) differ significantly 
Table 4 Body mass index (BMI) and prevalence of obesity $\left(B M I \geq 30 \mathrm{~kg} / \mathrm{m}^{2}\right.$ ) in Belgian men at work adjusted for age, region, marital status and educational level for the four study periods. For BMI, results are shown as regression coefficients $(B)$ and standard errors (SE). For percentages of $B M l \geq 30 \mathrm{~kg} / \mathrm{m}^{2}$ results are shown as odds ratios (OR) and $95 \%$ confidence intervals $(95 \% \mathrm{CI})$

\begin{tabular}{lll}
\hline Study period & \multicolumn{1}{c}{$\begin{array}{c}B M I \\
B(S E)\left(\mathrm{kg} / \mathrm{m}^{2}\right)\end{array}$} & $\begin{array}{c}B M I \geq 30 \mathrm{~kg} / \mathrm{m}^{2} \\
\text { OR }(95 \% \mathrm{Cl})\end{array}$ \\
\hline $1977-1978$, PFS (ref) & 0.00 & 1.00 \\
1979-1984, BIRNH & $0.59(0.11)^{* * *}$ & $1.38(1.11 ; 1.73)^{* *}$ \\
1986-1991, MONICA & $0.81(0.15)^{* * *}$ & $1.97(1.50 ; 2.58)^{* * *}$ \\
1992-1993, ORCA & $0.99(0.19)^{* * *}$ & $1.98(1.40 ; 2.80)^{* * *}$ \\
\hline
\end{tabular}

${ }^{* *} P<0.01 ;{ }^{* *} P<0.0001$; (ref) $=$ reference group.

from that of the inhabitants in the two respective regions taken as a whole?' We tested this hypothesis on a representative sample of the Belgian adult population (BIRNH) and found no significant differences - neither in mean BMI, nor in the prevalence of obesity - between Charleroi and the Southern region, and between Gent and the Northern region. Therefore, we concluded that the observed trends in obesity over the study periods were probably not due to regional differences between studies. Furthermore, differential participation rates between the four studies may also contribute to the observed differences in mean BMI and in prevalence of obesity over time. For instance, Sonne-Holm et $a l^{23}$ reported that the percentage of non-response was significantly higher in the obese than in the normal weight subjects $(42 \% v s$ $25 \%$ ), suggesting a positive relation between BMI and non-response. Applying this concept to our study, the increase in obesity over time cannot be attribute to differences in response rates, as the non-response rate was higher in 1979-1984 and 1986-1991 than in 1977-1978 and 1992-1993.

Finally, to minimize the sociodemographic differences between studies, we tested the effect of study period on mean BMI and the prevalence of obesity in a multivariate model, correcting for potential confounders including age, region, marital status and level of education, which are also associated transversely to obesity. In multivariate analysis, mean BMI still increased by $0.99 \mathrm{~kg} / \mathrm{m}^{2}$ between 1977 and 1992 . Prevalence of obesity had almost-doubled during this period (adjusted OR $=1.98$ ).

From the multivariate analysis, we would postulate that Belgium does not derogate to the general rise in prevalence of obesity reported during the last decade for other European countries, ${ }^{2-8}$ as well as for the US, $^{9,10}$ Canada $^{11}$ and Australia. ${ }^{12}$

However, in our subsample of working men aged $40-54 \mathrm{y}$, the rise in mean BMI, as well as the increase in the prevalence of obesity, were most pronounced between 1977-1978 and 1979-1984; between 19861991 and 1992-1993 the two obesity indices remained stable.

Similar changes have been reported in neighbouring countries, even though the study population characteristics and age range were different. For instance, in the Netherlands, ${ }^{3}$ mean BMI increased by $0.5 \mathrm{~kg} / \mathrm{m}^{2}$ in men with a mean age of $40 \mathrm{y}$ during the period 1974-1980; this was also reflected by a rise in the prevalence of obesity, from 3.3-5.6\%. But no change in mean BMI and in the prevalence of obesity were observed in Dutch men with a mean age of $35 \mathrm{y}$ between 1981-1986. In Germany, ${ }^{7}$ mean BMI remained stable in middle-aged men over the period 1985-1990, and the prevalence of obesity in males aged $40-49 \mathrm{y}$ and $50-59 \mathrm{y}$, which was already very high in 1985 (16.5\% and $22.9 \%$, respectively) only increased slightly between 1988 (16.7\% and $21.5 \%$, respectively) and 1990 (17.7\% and 23.2\%, respectively). In the $\mathrm{UK}^{2},{ }^{2}$ prevalence of obesity in men aged $16-64$ y increased dramatically from $6 \%$ in $1980,7 \%$ in $1986 / 1987$, to $13 \%$ in 1991 .

The strong time trends we observed in the prevalence of obesity in men with lower levels of education compared to those with a higher educational level, have also been observed in The Netherlands ${ }^{4}$ among younger subjects. In Belgium, the level of education is also inversely related to the incidence of fatal coronary heart disease. ${ }^{24}$ This relationship could, at least partially, be related to obesity and its constellation of CHD risk factors (low HDL-cholesterol, high triglyceridaemia, diabetes, high plasma fibrinogen).

Although our approach contains some shortcomings, we have some evidence from the multivariate analysis to suggest that obesity has increased in Belgium during the last decade, at least among working middle-aged men. In order to develop national guidelines for prevention and treatment of obesity, our results should be confirmed prospectively and at the general population level.

\section{References}

1 World Health Organisation (WHO). Prevention and management of the global epidemic of obesity. Report of the WHO Consultation on Obesity (Geneva), 3-5 June 1997). WHO: Geneva.

2 Department of Health. The health of the nation: one year on ... a report on the progress of the health of the nation, HMSO: London, Department of Health, 1993.

3 Blokstra A, Kromhout D. Trends in obesity in young adults in The Netherlands from 1974 to 1986. Int J Obes 1991; 15: 513-521.

4 Seidell JC, Verschuren WMM, Krombout D. Prevalence and trends of obesity in The Netherlands 1987-1991. Int J Obes 1995; 19: 924-927.

5 Jalkanen L, Tuomilehto J, Nissinen A, Puska P. Changes in body mass index in a Finnish population between 1972 and 1982. J Intern Med 1989; 226: 163-170.

6 Kuskowska-Wolk A, Bergström R. Trends in BMI and prevalence of obesity in Swedish men 1980-89. J Epidemiol Commun Health 1993; 47: 103-108.

7 Hoffmeister H, Mensink GBM, Stozenberg H. National trends in risk factors for cardiovascular disease in Germany. Prev Med 1994; 23: 197-205.

8 Gutierrez-Fisac JL, Redigor E, Rodriguez C. Trends in obesity differences by educational level in Spain. J Clin Epidemiol 1996; 49: 351-354. 
9 Burke GL, Sprafka JM, Folsom AR, Luepker RV, Norsted SW, Blackburn H. Trends in CHD mortality, morbidity and risk factor levels from 1960 to 1986: the Minnesota Heart Study. Int J Epidemiol 1989; 3 (suppl 1): S73-S81.

10 Kuczmarski RJ, Flegal KM, Campbell SM, Johnson CL. Increasing prevalence of overweight among US adults: the national health and nutrition examination surveys, 1960 to 1991. JAMA 1994; 272: 205-211.

11 Millar WJ, Stephens I. Social status and health risks in Canadian adults: 1985 and 1991. Health Reports 1993; 5: $143-156$.

12 Boyle CA, Dobson AJ, Egger C, Magnus P. Can increasing weight of Australians be explained by decreasing prevalence of cigarette smoking? Int J Obes 1994; 18: 55-60.

13 Sobolski J, De Backer G, Degre S, Kornitzer M, Denolin H. Physical Activity, Physical Fitness and Cardiovascular Diseases. Design of a prospective epidemiologic study. Cardiology 1981; 67: 38-51.

14 De Baker G. Nutrition and Health: an Interuniversity study. Regional differences in dietary habits, coronary risk factors and morbidity rates in Belgium. 1. Design and Methodology. Acta Cardiol 1984; 39: 285-292.

15 WHO MONICA Project Principal Investigators: the World Health Organization MONICA Project (Monitoring of Trends and Determinants in Cardiovascular Disease): a major international collaboration. J Clin Epidemiol 1988; 41: $105-114$.

16 De Boever E, De Bacquer D, Braeckman L, Gaele G, Rosseneu M, De Backer G. Relation of fibrinogen to lifestyle and to cardiovascular risk factors in a working population. Int J Epidemiol 1995; 24: 915-921.
17 Kleinbaum DG, Kupper LL, Muller KE (eds). Applied Regression Analysis and Other Multivariable Methods (2nd edn). PWSKENT Publishing Company, Wadsworth, Inc: Boston, 1988.

18 Kornitzer M, Bara L. For the BIRNH Study Group. Differences between North and South in coronary risk factors, food habits and mortality in Belgium. Acta Cardiol 1989; 44: $145-155$.

19 Van Houte O, Kesteloot H. An epidemiological survey of risk factors for ischaemic heart disease in 42804 men. I. Serum cholesterol value. Acta Cardiol 1972; 27: 527-564.

20 Kornitzer M, De Backer G, Dramaix M, Thilly C. Regional differences in risk factor distributions, food habits and coronary heart disease. Mortality and morbidity in Belgium. Int $J$ Epidemiol 1979; 8: 23-31.

21 Joossens JV, Vuylsteek K, Brems-Heyns E, Carlier J, Claes JH, De Backer G, Graffar M, Kesteloot H, Kornitzer M, Lequime J, Pannier R, Raes A, Van Houte O, Vastesaeger $\mathrm{M}$, Verdonk G. The pattern of food and mortality in Belgium. Lancet 1977; 1 (8021): 1069-1072.

22 De Craene I, De Backer G, Kornitzer M, De Henauw S, Bara L, Rosseneu M, Vercaemst R. Determinants of fat consumption in general population. Rev Epidemiol Santé Publique 1990; 38: 539-543.

23 Sonne-Holm S, Sørensen TI, Jensen G, Schnohr P. Influence of fatness, intelligence, education and sociodemographic factors on response rate in a health survey. $J$ Epidemiol Commun Health 1989; 43: 369-374.

24 Kittel FM, Doyen MP, Koyuncu R, De Backer G, Kornitzer M. Socio-denmograhic determinants of CHD mortality in a Belgian general population. The BIRNH study [Abstract]. Can J Cardiol 1997; 13 (suppl B): 173B. 